\title{
JÓVENES Y CONFIANZA POLÍTICA EN UN CONTEXTO DE DESESTABILIZACIÓN SOCIAL E INSTITUCIONAL. UN ESTUDIO COMPARATIVO EN PAÍSES DE LA CUENTA DEL MEDITERRÁNEO
}

\author{
M. ÀNGELS CABASÉS* \\ CARLES FEIXA ${ }^{* *}$ \\ ROGER CIVIT $^{* * *}$
}

\begin{abstract}
RESUMEN
En los últimos años y en países del norte y sur del Mediterráneo, han surgido movimientos juveniles de protesta hacia las instituciones políticas y económicas, de los cuales destacan la «primavera árabe» y los «indignados» en España, modelos que han desarrollado formas de actuación diferentes. El presente artículo discute dos cuestiones básicas: ¿Responden ambos casos a situaciones socioeconómicas distintas? ¿Existen factores compartidos? A través de la explotación de datos demoscópicos, procedentes de encuestas internacionales, se pretende analizar un conjunto de causas económicas y sociales que han podido influir en la creciente desconfianza de este colectivo hacia los gobiernos de sus respectivos países.
\end{abstract}

PALABRAS CLAVE: DESAFECCIÓN, POLÍTICA, ANÁLISIS MULTINIVEL, DESEMPLEO JUVENIL, EDUCACIÓN, PRIMAVERA ÁRABE, INDIGNADOS, 15M

* Doctora en Economía. Profesora Titular de Economía Aplicada, Universidad de Lleida (UDL) (Cataluña-España). Investigadora del Centro de Estudios sobre Juventud y Sociedad (JOVIS-UDL).

E-Mail: macabases@econap.udl.es.

** Doctor en Antropología Social. Catedrático de Antropología Social, Universidad de Lleida (UDL) (Cataluña-España). Investigador Principal del Centro de Estudios sobre Juventud y Sociedad (JOVIS-UDL).

E-Mail: feixa@geosoc.udl.es.

*** Sociólogo y Máster en Análisis Político y Asesoría Institucional, Universidad de Barcelona (UB). Investigador vinculado a grupos de investigación de la Universidad de Barcelona y Universidad de Lleida (UDL). E-Mail: civitcarbonell@gmail.com. 


\title{
JOVENS E CONFIANÇA POLÍTICA EM UM CONTEXTO DE DESESTABILIZAÇÃO SOCIAL E INSTITUCIONAL. UM ESTUDO COMPARATIVO NOS PAÍSES DA BACIA DO MEDITERRÂNEO
}

\begin{abstract}
RESUMO
Nos últimos anos, e nos países do norte e sul do Mediterrâneo, têm surgido movimentos de protesto da juventude contra as instituições políticas e econômicas que incluem a «primavera árabe» e os «indignados» na Espanha, modelos que desenvolveram formas de desempenho diferentes. Este artigo discute duas questões básicas: Estes casos reagem a situações socioeconômicas diferentes? Existem fatores em comum? O objetivo é analisar um conjunto de causas econômicas e sociais que influenciaram a crescente desconfiança destes grupos pelos governos de seus respectivos países através da exploração de dados demoscópicos de enquetes de opinião internacionais.

PALAVRAS CHAVE: DESAFEIÇÃO POLÍTICA, ANÁLISE MULTINÍVEL, DESEMPREGO JUVENIL, EDUCAÇÃO, PRIMAVERA ÁRABE, INDIGNADOS

\section{YOUNG PEOPLE AND POLITICAL TRUST IN A CONTEXT OF SOCIAL AND INSTITUTIONAL DESTABILIZATION A COMPARATIVE STUDY IN COUNTRIES OF THE MEDITERRANEAN BASIN}

\begin{abstract}
In recent years and in the North and South of the Mediterranean have emerged several youth protest movements against political and economic institutions, which include the «arab spring» and the «15M» in Spain, two models that took different ways and achieved unequal results. This paper discusses about two basic questions: do they respond to different socioeconomic situations and which shared factors are there? Through the exploitation of opinion polls data from international surveys, the objective of this article is to analyse a set of economic and social agents that have influenced the growing distrust of this group towards the governments of their respective countries.
\end{abstract}

KEY WORDS: DISAFFECTION POLICY, MULTILEVEL ANALYSIS, YOUTH UNEMPLOYMENT, EDUCATION, ARAB SPRING, 15M 


\section{INTRODUCCIÓN}

EN UN NÚMERO ANTERIOR de esta revista, uno de los coautores de este texto publicó un artículo en coautoría, en el que se comparaba el movimiento de los «indignados» o del 15-M con movimientos sociales anteriores, focalizando en las prácticas comunicativas de los jóvenes (Fernández-Planells, Feixa y Figueras, 2013). En este nuevo artículo retomamos el análisis comparativo desde una perspectiva complementaria, pasando de la comparación diacrónica entre movimientos sociales de épocas distintas a la comparación sincrónica entre movimientos sociales de la misma época en distintos países de la misma área geográfica, el norte y el sur del Mediterráneo. En este caso, nos centraremos en los aspectos económicos y políticos, intentando desentrañar las similitudes y diferencias entre movimientos como la «primavera árabe» y los «indignados», en relación con las estructuras laborales e institucionales que condicionan la vida de los jóvenes en los respectivos países. ${ }^{1}$

Tras seis años de crisis económica y financiera la actividad económica mundial se recupera gradualmente, aunque de forma débil ${ }^{2}$ y con diferencias en las perspectivas de crecimiento entre países cada vez mayores, ${ }^{3}$ factores que inciden fuertemente en la recuperación del mercado de trabajo.

La Organización Internacional del Trabajo (OIT) en su Informe Tendencias mundiales del empleo 2014 ¿Hacia una recuperación sin creación de empleos?, ${ }^{4}$ pone de manifiesto que el empleo «crece a un ritmo más lento que la fuerza de trabajo» y a su vez el Fondo Monetario Internacional (FMI) apunta a un crecimiento más débil para los próximos años en algunas economías europeas, entre otros factores, debido al elevado nivel de desempleo. La OIT reitera la necesidad de destinar más recursos a las políticas sociales y del mercado de trabajo y a políticas cuya finalidad sea abordar la inactividad y el desajuste de las competencias, teniendo en cuenta que aproximadamente 23 millones de personas han abandonado el mercado de trabajo por desánimo.

1 Mientras el primer artículo se basaba en un proyecto financiado por el Ministerio de Economía y Competividad de España (GENIND: CSO201234415), el segundo se inscribe en un proyecto financiado por la Unión Europea (SAHWA:FP7-SSH.2013.4.1-2-613174).

2 Boletín mensual, julio de 2014. Banco Central Europeo.

3 Fondo Monetario Internacional (julio 2014). Perspectivas de la Economía Mundial (Informe WEO).

4 Disponible en: www.ilo.org. 
Insiste que ante un aumento de 1,2\% del PIB en los países de la OCDE, podrían crearse 3,9 millones de empleos en la región de las economías desarrolladas y la Unión Europea (UE).

Las personas jóvenes son las más afectadas por la situación actual. Según el mismo informe, actualmente a nivel mundial hay 75 millones de este colectivo desempleadas (de 16 a 24 años) y la relación mundial empleo/población juvenil ha pasado de 44,8\% en 2007 a $42,3 \%$ en 2013 . Desde 2009 , la propia OIT, ya venía reclamando la adopción de medidas por parte de los distintos gobiernos para dar respuesta a la crisis económica y financiera y su impacto sobre el empleo. Muestra de ello es la Conferencia Internacional del Trabajo de $2009,{ }^{5}$ en la cual se adoptó, por unanimidad un Pacto Mundial para el Empleo entre representantes de los gobiernos, agentes económicos y sociales (actores de la economía real), ${ }^{6}$ un pacto basado en el programa de trabajo decente que permita a los trabajadores tener empleos en los que puedan utilizar de la mejor manera posible sus conocimientos y habilidades y contribuir de esta manera al máximo bienestar común.

El empleo juvenil es uno de los retos más importantes que los países deben abordar, especialmente en aquellos que presentan elevadas tasas de paro. Solo en Europa se contabilizan 7,5 millones de NEET; es decir, jóvenes que ni estudian ni trabajan ni siguen formación, ${ }^{7}$ lo que representa un 12,9\% de los jóvenes europeos menores de veinticinco años, teniendo en cuenta que, según los últimos datos facilitados por EUROSTAT, la tasa de paro juvenil europea alcanza el 23\% al segundo trimestre de 2013 superando el doble de la tasa correspondiente a los adultos $(10,9 \%)$ y mientras el $34,1 \%$ de las personas en paro menores de veinticinco años llevan más de doce meses sin trabajo. ${ }^{8}$

5 Nonagésima octava reunión, Ginebra, 19 de junio de 2009.

6 Para recuperarse de la crisis: un pacto mundial para el empleo. Conferencia Internacional del Trabajo, en su nonagésima octava reunión, Ginebra, 19 de junio de 2009.

7 Acrónimo en inglés: «Not in Employment, Education and Training»

8 Ante este panorama la UE viene planteando un conjunto de iniciativas de diverso contenido que derivarán en la Propuesta de la Comisión de 5 de Diciembre de 2012, de Recomendación del Consejo relativa al establecimiento de la Garantía Juvenil (COM (2012) 729 final de 5 de Diciembre de 2012) que, finalmente, se adoptará por el Consejo en abril de 2013 (Véase diario oficial de la Unión Europea de 26 de abril). 
No afrontar esta situación adecuadamente puede suponer el empobrecimiento social y económico para una generación que en ningún caso ha sido la causante de la situación actual. Entre las consecuencias del orden social cabe mencionar fenómenos como la desconexión de la sociedad y la desconfianza hacia el sistema político, unos niveles reducidos de autonomía, el temor a lo desconocido o el desperdicio de cerebros, brainwaste. ${ }^{9}$

En particular en este artículo, se analiza hasta qué punto la confianza hacia el sistema político y las instituciones gubernamentales, por parte de las personas jóvenes menores de treinta años, ${ }^{10}$ está influida por la actual crisis del empleo juvenil entre otros factores económicos y sociales, individuales y de país. El estudio se circunscribe en Europa y en un conjunto de países árabes en los cuales la juventud ha protagonizado, en los últimos años, importantes movilizaciones de protesta y de reclamación de cambios sociales. Cabe señalar que no es objeto de este artículo el análisis en profundidad de la situación política, económica y social de dichos países.

Ante esta tarea, se han analizado dos encuestas internacionales que cuentan con un elevado reconocimiento académico: la Encuesta Social Europea $(\mathrm{ESE})^{11}$ que en su última edición recoge datos de veintinueve estados del continente europeo (incluyendo Rusia e Israel) y la Encuesta Mundial de Valores (WVs) ${ }^{12}$ la cual, en su sexta edición, pone a disposición datos de hasta cincuenta y cinco países de los cinco continentes.

\section{a) El desempleo juvenil y sus consecuencias en Europa}

Una de cada cinco personas jóvenes europeas dispuestas a trabajar no encuentra trabajo, siendo una problemática a la que Europa hace décadas que no se enfrentaba. No sólo son los estados del sur y del este de Europa los que presentan más paro (desempleo) como se observa en el

9 Dictamen del Comité Económico y Social Europeo sobre Promover el empleo juvenil. Diario Oficial de la Unión Europea de 6 de junio de 2013.

10 Se consideran las personas jóvenes menores de 30 años en línea con organismos internacionales (OIT, OCDE y Comisión Europea) que ponen de manifiesto la importancia relativa del colectivo de 25 a 29 años en el total del conjunto de la población juvenil.

11 Correspondiente a la sexta oleada de la Encuesta Social Europea. Disponible en: www.europeansocialsurvey.org.

12 Correspondiente a la sexta oleada de la Encuesta World Values Survey. Disponible en: www.worldvaluessurvey.org. 
gráfico 1, sino también los que muestran una mayor diferencia entre el paro general y el paro juvenil. ${ }^{13}$ Específicamente las tasas de paro más altas son las de Grecia y España, con valores superiores al 50\%, valores que no solo se explican por la actual crisis, sino que en los años precedentes, por motivos estructurales de las correspondientes economías, ya presentaban valores superiores a la media europea.

El descenso del empleo es, pues, uno de los retos a los que se enfrenta Europa, y con mayor énfasis en los países del sur (Grecia, España y Portugal), los cuales no son capaces de crear suficientes empleos debido, en parte, a un tejido productivo con poca o nula capacidad de contratación (Belil, 2014) y por otra, a las medidas impuestas por sus Gobiernos que están incrementando, entre las personas jóvenes, una ocupación precaria y temporal. ${ }^{14}$

GRÁFICO 1: TASA DE PARO DE LOS PAÍSES DE LA UNIÓN EUROPEA 2014

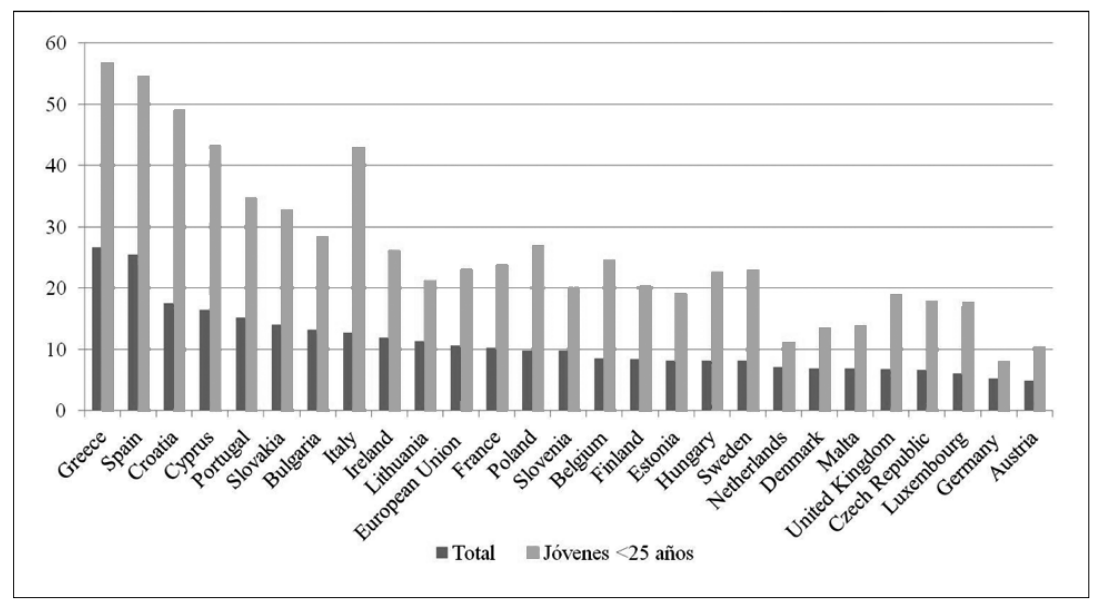

Fuente: Elaboración propia a partir de datos Euroestat.

13 Como indican numerosos estudios, el paro juvenil es mayor en el colectivo masculino que en el femenino, entre los menores de 25 años y menor a medida que se posee un nivel formativo más alto. Entre ellos: Camprubí, 2013.

14 «Tendencias mundiales del empleo 2014: ¿hacia una recuperación sin creación de empleos?». Ginebra, enero 2014. 
Reto al que cabe sumar las alarmantes cifras del colectivo de NEET que se sitúan alrededor del $20 \%$ del total de personas jóvenes menores de treinta años. ${ }^{15}$

Desde 2010, Europa ha impuesto la reducción del déficit público como prioridad, con el objetivo de calmar los mercados financieros, $\mathrm{y}$, en consecuencia, abandonando la estrategia de creación y mejora del empleo que en tantas reuniones del G20 y otros foros internacionales se había reclamado. ${ }^{16}$ En este marco, la mayoría de los países avanzados han flexibilizado la legislación laboral con la esperanza que los mercados financieros, de nuevo, reaccionen positivamente y estimulen el crecimiento y la creación de empleo. A pesar de ello, los países que han aplicado con mayor intensidad las políticas de austeridad y de liberalización, los del sur de Europa, el empleo y el crecimiento siguen deteriorándose. Estas medidas aplicadas en un contexto de escasas perspectivas de demanda y con un sistema financiero en un proceso de desendeudamiento e incapaz de fomentar la inversión privada han provocado un bucle: debilitamiento del crecimiento económico, mayor volatilidad y mayor contracción del crédito, dando lugar a menor inversión y aumento del desempleo. Una contención que ha menoscabado el conjunto de políticas públicas, especialmente las dirigidas al fomento de la creación de empleo y que, sin embargo, no ha afectado al poder financiero que, al contrario, ha recibido las ayudas económicas para poder sanear su situación. ${ }^{17}$ Las medidas de austeridad, a su vez, han impactado negativamente sobre los profesionales de las políticas juveniles (despidos, peores condiciones, contrataciones de bajo nivel) y sobre los programas gubernamentales de atención y promoción juveniles de forma directa o indirecta a través de otros programas departamentales (So-

15 Según EUROSTAT, en esta definición se incluyen jóvenes a) que no están empleados (es decir, en paro o inactivos según la definición de la Organización Internacional del Trabajo) y b) que no han recibido ningún tipo de educación o formación en las cuatro semanas anteriores a la encuesta. Y según la misma fuente, España presentaba una tasa de NEET en 2012 del 18,8\%, una tasa que sólo supera Bulgaria (21,5\%) e Italia $(21,1 \%)$. Por su parte, Grecia es el país que más ha incrementado dicho colectivo desde 2007 (un 8,8 pp), seguido de España que ha pasado del $12,1 \%$ antes de iniciarse la crisis, al $18,8 \%$ en 2012 , es decir, ha aumentado el porcentaje de NEET en 6,6 pp.

16 OIT (2012): «Informe sobre el trabajo en el mundo 2012. Mejores empleos para una economía mejor». Ginebra.

17 «Otro rescate portugués». El País, 25 de agosto de 2014. 
ler, Planas y Feixa, 2014). Como indica Joan Subirats (Subirats y León, 2014), existe un claro sesgo generacional de los responsables públicos respecto a la población juvenil que provoca una despreocupación real y palpable hacia su situación. Las políticas de juventud, muchas veces enfocadas hacia el ocio o la formación en ámbitos no profesionales, han desprendido una imagen de paternalismo que no ha hecho más que alejar a la juventud de sus élites políticas.

Muchas personas jóvenes han visto imposibilitada la emancipación completa en sus trayectorias vitales (Muñoz, 2009). Y muchos de aquellas que habían podido iniciar el proceso de emancipación se han visto obligadas a retornar al hogar familiar y en algunos casos a depender de ayudas de asistencia social (Moreno, López y Salgado, 2012). En este sentido ha producido cierto retorno al modelo de bienestar mediterráneo propuesto por Esping-Andersen (1999): un modelo basado en las ayudas familiares como airbag y con el importante papel de la solidaridad comunitaria, alejado de los modelos con más intervención del Estado o de las iniciativas privadas correspondientes al norte y al oeste de Europa.

Otras personas jóvenes han visto como única solución emigrar a otros países en busca de nuevas oportunidades laborales (Navarrete, 2014). Los destinos se han concentrado en los países del centro y norte de Europa, en algunas ocasiones buscando un trabajo de forma autónoma y en otros de forma organizada dentro del marco de los programas institucionales o campañas empresariales. Según datos de EURES, la red europea de búsqueda de trabajo - y para el caso español desde el inicio de la crisis económica-, más de 320.000 personas jóvenes habrían registrado su currículum y más de 260.000 (Navarrete, 2014) habían tomado la iniciativa de marchar del país para ocupar puestos de trabajo con una calificación inferior a su perfil formativo.

Esta situación descrita, crisis del mercado juvenil y falta de políticas públicas dirigidas a la juventud, han sido, sin duda, un caldo de cultivo para la desafección de la juventud del sur de Europa hacia sus dirigentes políticos como se desprende de los datos del gráfico 2 , procedentes de la encuesta ESE. 
GRÁFICO 2: CONFIANZA EN LOS POLÍTICOS DE LAS PERSONAS JÓVENES EUROPEAS (MENORES DE 30 AÑOS)

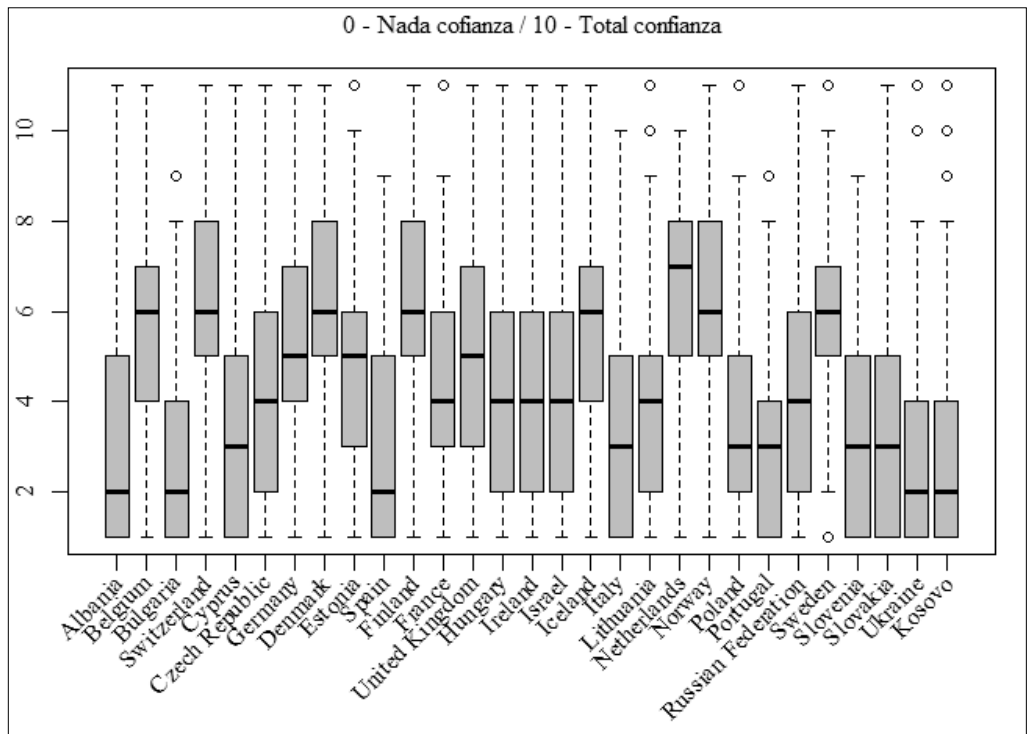

Fuente: elaboración propia a partir de los datos de la Encuesta Social Europea (ESS)

La respuesta más explícita a la situación hasta aquí detallada, ha sido la aparición de una conciencia de fuerte protesta ciudadana expresada en las principales calles de Portugal, España, Italia o Grecia. Quizás el caso más paradigmático es el que se vivió en España en mayo de 2011 cuando miles de personas jóvenes ocuparon las plazas de las principales ciudades con el objetivo de crear espacios para el debate y reflexión sobre el modelo económico y político en el que estaban inmersos. A estos jóvenes se les identificó con el término «indignados», haciendo una referencia explícita al libro Indignez-vous! del diplomático francés Stéphane Hessel (2011), editado unos meses antes de estas movilizaciones y que logró divulgar su crítica al actual sistema político y económico a un gran número de lectores de todo el continente. Las movilizaciones de los indignados se extendieron - ciertamente con menor seguimiento- por diferentes países del mundo occidental. Su mayor éxito consistió en agrupar $^{18}$ varias reivindicaciones que hasta el momento se

18 «Los indignados de toda Europa salen a la calle para clamar contra el ‘austericidio' de la troika». El Periódico, 1 de junio de 2013. 
habían defendido separadamente por múltiples movimientos sociales ${ }^{19}$ (Fernández-Planells, Feixa y Figueras, 2013).

No obstante, dichas movilizaciones no se pueden entender en clave estrictamente nacional. A pesar de que en cada Estado se personalizó algunas de las críticas hacia las élites regionales, el grueso de las reivindicaciones eran hechas contra un sistema internacional de relaciones entre el poder económico y el político. Esta unidad ha ayudado a crear una conciencia transnacional que identifica los Estados mediterráneos de Europa en contraposición a los del centro y norte del continente.

\section{b) Las causas de las revoluciones árabes explicadas a través de los factores sociolaborales}

En las últimas décadas uno de los mayores procesos vividos en los países árabes del sur y este del Mediterráneo ha sido la creciente demanda de empleo, fruto de una explosión de natalidad sin precedentes y de la incorporación de la mujer en el mercado laboral. Aunque este incremento de mano de obra no se ha considerado, por parte de los poderes públicos de la región, como una oportunidad. Todo lo contrario, ha preocupado a sus gobiernos que, en el mejor de los casos han enfocado la nueva situación como un reto, y en el peor de ellos como un desafío.

Como sucede en el sur de Europa actualmente, el desempleo es una de las mayores problemáticas de la región, especialmente entre las personas jóvenes de entre quince y veinticuatro años, donde según estimaciones de la OIT y a excepción del año 2008, se ha mantenido una tasa de paro superior al 20\% del año 2005 hasta la actualidad. Unas tasas que se manifiestan notablemente superiores a las tasas de las regiones desarrolladas de la Europa continental y nórdica, como se observa en el gráfico 3 .

En los últimos años los diferentes países árabes han dado grandes pasos para mejorar el acceso a una educación de calidad, invirtiendo en políticas de educación el equivalente al 4,8\% de su PIB en el periodo 2006-2009, permitiendo multiplicar la media de años de escolarización de 1,1 años a 5,9 años (Hammam, 2012). Sin embargo, los resultados en materia de educación siguen por debajo de la media internacional y no han podido evitar la baja productividad y el aumento del paro.

19 «El sur de Europa le enseña los dientes a la austeridad». Público,14 de noviembre de 2012. Disponible en: www.publico.es. 
GRÁFICO 3: TASA DE DESEMPLEO JUVENIL (15 A 24 AÑOS) POR ZONAS DE ESTUDIO

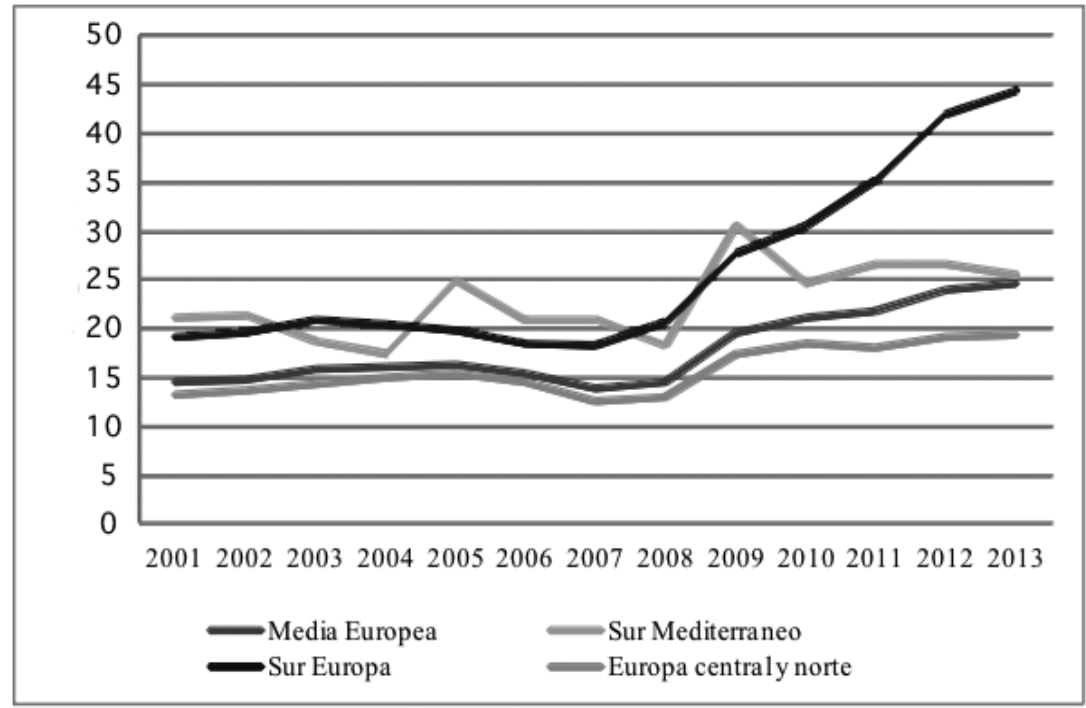

Fuente: elaboración propia a partir de datos de ILOSTAT para los países utilizados en este estudio.

Algunos expertos (Hammam, 2012) señalan que la poca capacidad económica para generar empleo está motivada, sobre todo, por la baja calidad del sistema educativo y a la falta de relación entre éste y las necesidades del mercado laboral. Una economía basada en la extracción y exportación de petróleo y en las remesas de los emigrados que en consecuencia no requiere de una mano de obra calificada.

En este contexto, la mayoría de personas jóvenes han visto frustradas sus expectativas para obtener un trabajo digno y calificado, y los que han alcanzado mayor formación, o bien han accedido a un trabajo de más baja calificación, y en consecuencia, de menor salario, o bien han emigrado. Tan solo una pequeña parte de la población árabe posee suficientes recursos para abrir un negocio propio. Además, en esta zona, los jóvenes cada vez dependen más de la educación privada, especialmente la secundaria y universitaria. Ello provoca una elitización de la formación de las familias con mayores ingresos y, a su vez, mayor facilidad para poder optar a los puestos de trabajo más privilegiados gracias al mayor peso que mantienen las conexiones personales y profesionales en relación a las propias competencias. 
En resumen, existe una carencia de políticas y de programas de apoyo al crecimiento económico y a la mejora de la productividad, y las que se desarrollan están enfocadas, principalmente, a las grandes empresas y las personas jóvenes con más recursos económicos. Estas políticas han permitido prosperar a un pequeño sector de la sociedad pero ha imposibilitado el crecimiento y la prosperidad de la mayoría de los ciudadanos. Además y, a diferencia de los vecinos de Europa, tan solo unos pocos países de la región tienen establecido algún plan de protección por desempleo. Por consiguiente, el Estado es el principal actor económico y empleador de la región, y el principal facilitador en todas las facetas básicas asistenciales, facilitando techo, alimentación y otros servicios de primera necesidad.

Las estrechas relaciones entre las élites económicas y políticas son, precisamente, uno de los mayores impedimentos para la competitividad, la creación de puestos de trabajo y en general el crecimiento de la economía. Los monopolios creados por las élites surgidas en pleno proceso de descolonización de los países árabes se han mantenido estables hasta la actualidad. Independientemente de la ideología de los mandatarios, la situación de control centralizado de la economía y el mantenimiento de privilegios han permanecido estables, sus esfuerzos han sido dirigidos a favorecer a las élites afines a los regímenes en contraposición a la promoción del bien común. Monopolios que han contribuido a la precariedad con la que conviven actualmente los jóvenes árabes (Malik y Awadallah, 2013).

Al mismo tiempo, el compromiso social en la defensa de los derechos colectivos ha sido obstaculizado por leyes restrictivas sobre el asociacionismo y creación de organizaciones no gubernamentales. En cambio, son permitidas habitualmente las organizaciones caritativas, que en muchas ocasiones están conectadas con la élite establecida, de modo que las ONGs. que trabajan en el ámbito de los derechos humanos también están restringidas (Khouri y Shelata, 2011). Y en particular, para el gran y creciente grupo de población activa que trabaja en el sector informal, la exclusión social debida a la falta de políticas de protección social provoca su exclusión económica y su incapacidad para organizar y desarrollar un compromiso sindical y social (Malik y Awadallah, 2013). En definitiva, décadas de liberalización económica, privatizaciones y precariedad laboral, han debilitado el movimiento sindicalista y la clase media, protagonistas necesarios para el cambio social.

No es de extrañar pues, que en 2011, desde las calles y las plazas de los países árabes sus reclamaciones estuvieran relacionadas con el 
fomento de la contratación y del emprendimiento, la demanda de una protección social universal y una mayor libertad en la regulación del movimiento asociativo en general y sindical en particular. Al mismo tiempo, las protestas también se dirigían a los sindicatos ya existentes para exigirles una mayor preocupación y dedicación de los problemas de las personas jóvenes y especialmente de las mujeres jóvenes, puesto que éstos sindicatos representan, en el mejor de los casos, a los trabajadores del sector público y en menor medida a los trabajadores de las medianas y grandes empresas, pero en ningún caso a los trabajadores de la economía informal, que ocupa la mayor parte de la población juvenil.

Las reivindicaciones de las diferentes «primaveras árabes» también han insistido en el reparto desigual de la riqueza, factor de crecimiento de la población en situación de exclusión social. Aunque en los países de la región se han establecido programas e inversiones contra la pobreza, tienen una larga tradición de falta de solidaridad social y familiar como se desprende de sus sistemas de gobierno y de la falta de políticas estatales para la seguridad social. Es necesario recordar que el desarrollo social y económico no solo se debe a la creación de riqueza, sino sobre todo, como ésta se distribuye y al acceso de la población para decidir el reparto a través de la participación política e institucional (Hammam, 2012).

En los últimos cuarenta años, de los diez países que han crecido más en términos de desarrollo humano, cinco son estado árabes: Omán, Arabia Saudita, Túnez, Argelia y Marruecos (Malik y Awada1lah, 2013), pero sin embargo, la pobreza persistente en la región como consecuencia de decisiones políticas concretas y no por falta de recursos y de oportunidades, como se ha relatado. Para afrontar efectivamente la pobreza, los Estados deberían asumir un rol de liderazgo en la expansión de las posibilidades de participación y el empoderamiento de la población. Esta es una agenda que requiere centrar una especial atención en el respeto de los derechos de la población y en garantizar su dignidad.

En el terreno democrático el desarrollo equitativo en las regiones árabes se ha dilatado debido a dos causas fundamentales. La primera - ya analizada - hace referencia al papel limitado de las asociaciones como organizaciones de control de la acción gubernamental y la segunda, la carencia en la capacidad de fiscalización por parte de la población hacia sus gobiernos. 
A pesar que los países árabes concurren regularmente a elecciones nacionales y locales, la calidad del proceso electoral, en general, presenta algunas carencias, especialmente con respecto a la administración electoral y la falta de competitividad y apertura de la información disponible. En este sentido, según la última oleada de la encuesta WVS (2010-2014), un altísimo porcentaje de personas jóvenes otorgan máxima puntuación al valor de la democracia, un $60 \%$ de los jóvenes no confía en su gobierno y prácticamente la mitad no considera honestas las elecciones. Esto es, una mayoría de jóvenes se muestra favorable hacia una mayor participación ciudadana, pero a su vez muestra bajas expectativas que sus gobernantes le permitan convertirse en ciudadanos activos, provocando que sus prioridades sigan siendo el trabajo, los estudios y la formación de una familia. En este sentido, la primavera árabe buscaba una mejora de la legitimidad de los liderazgos a través de elecciones libres y limpias, en un ambiente de libertad de expresión y de organización.

Bajo estas circunstancias, los ciudadanos salieron a la calle para afirmar su rol central y reclamar mecanismos efectivos contra la corrupción y para poder fiscalizar también las estructuras políticas y, a su ve, un sistema judicial realmente independiente del ejecutivo. La impunidad de las élites políticas, económicas y administrativas en un contexto de restricción de las libertades civiles y comunitarias, han alejado a la población árabe, y especialmente a sus personas jóvenes, de un crecimiento económico equitativo.

\section{CONTEXTO DE LAS PROPUESTAS: 15M Y PRIMAVERAS ÁRABES}

Aparentemente las protestas ciudadanas acaecidas en diferentes países del sur del Mediterráneo - y de otros Estados árabes- tenían motivaciones diversas. Sin embargo, desde una visión amplia se pueden observar factores económicos y sociales comunes: laborales, relacionados con las desigualdades sociales y los relacionados con el sistema político y de participación.

Nadie predijo la movilización que se inició el 15 de mayo de 2011 en las principales plazas de España. Las manifestaciones de protesta protagonizadas por las personas jóvenes de Grecia y Portugal podían ser más esperables, incluso previsibles, pero el movimiento $15 \mathrm{M}$ no lo era. Como tampoco lo fueron las revueltas árabes iniciadas el mismo año y que desde Túnez se extendieron a la mayoría de los estados de la región del sur del Mediterráneo. Toda la apatía que pa- 
recía palpable por parte de la juventud ante las diferentes situaciones que vivían, de repente se transformó en un activismo social, político y económico. Y nadie lo esperaba (Atentas y Vivas, 2011).

Hasta entonces la implicación activa de la juventud de las dos orillas del Mediterráneo se circunscribía a formar parte de asociaciones politizadas —en una medida muy limitada en los Estados árabescomo partidos políticos y sindicatos, y de organizaciones no gubernamentales a través del ejercicio del voluntariado. Y la movilización se limitaba a sus formas más tradicionales: manifestaciones, petición de firmas, boicots, etcétera. Las protestas lograron cambiar estas dinámicas y organizar a la juventud (no solo) entorno a debates de transformación social y los llevó a participar activamente en redes sociales o en otros tipos de plataformas digitales inexistentes hasta el momento.

¿Qué es lo que motivó a tantas personas jóvenes a movilizarse de esta forma tan activa? Los investigadores han apuntado e identificado una gran diversidad de causas, y muchas de ellas no compartidas en todas las movilizaciones. En este texto pretendemos relacionar tales causas, con las características socioeconómicas actuales de la juventud en los respectivos países, para entender qué influyó en la frustración manifestada hacia las estructuras políticas y empresariales y el crecimiento de las nuevas formas de participación. En definitiva, qué factores han influido en la desconfianza creciente hacia sus respectivos sistemas políticos.

Como ya se ha apuntado, las movilizaciones juveniles difícilmente se habrían producido sin el uso de las redes sociales y los dispositivos electrónicos de bolsillo. Ciertamente, el mundo ha vivido varias experiencias de movilización, incluso masiva, mucho antes de la aparición de estas tecnologías. Pero la posibilidad de estar permanentemente conectado e informado de los acontecimientos del entorno o de otro punto lejano es solo propia de las redes sociales.

Y aún más importante, las nuevas tecnologías permiten la posibilidad de tomar parte, participar y poder aportar cualquier opinión con cualquier otro individuo desconocido o grupo creado ad hoc en cualquier momento y en cualquier espacio físico. En este sentido, se puede afirmar que para entender la emergencia de muchos de los movimientos de protestas producidos en la actual década $-15 \mathrm{M}$, primaveras árabes, Occupy Wall Street, Yosoy132, entre otros-han sido esenciales un gran número de nuevas e innovadoras herramientas online (FernándezPlanells, Feixa y Figueras, 2014). 
Esto ha permitido el crecimiento de una masa crítica formada mayoritariamente por personas jóvenes. ${ }^{20}$

Los jóvenes protagonistas de estos movimientos de protesta han adaptado sus propios canales de comunicación y difusión en los medios a los que poseen mayor facilidad de acceso, esto es, a las redes sociales, blogs, wikis, etcétera (Fernández-Planells, Feixa y Figueras, 2013). También, cabe señalar, que ha posibilitado una mayor participación de las mujeres, a menudo excluidas de las arenas públicas tradicionales en la región árabe. Tanta ha sido la capacidad de movilización de las redes sociales que algunos de los regímenes árabes han probado incluso de limitar su acceso controlando las comunicaciones tecnológicas. Pero este no es un canal tan fácilmente controlable como los medios de comunicación tradicionales (Malik y Awadallah, 2013).

De sus reivindicaciones se desprende que las protestas del norte y sur del Mediterráneo estuvieron motivadas, principalmente, por la falta de oportunidades económicas y por una alta desocupación. Países del sur de Europa han vuelto a revivir capítulos de pobreza que ya parecían olvidados de las etapas no democráticas. La desigualdad creciente en las sociedades de ambas orillas, con una clase empresarial y política instaladas en un nepotismo institucional, muy especialmente en la zona árabe, hizo el resto. Un cóctel inflamable al que se añade diferentes casos de corrupción aparentemente impermeables al peso de la justicia. Contra esta situación, la presión social para combatir la corrupción y las malas prácticas institucionales no ha parado de aumentar en estos países, canalizada a través de la participación juvenil y la creación de diferentes movimientos de protesta (Hammam, 2012).

Los sistemas tradicionales de participación ya no resultan útiles para una gran parte de la población, especialmente la más joven. La participación en las elecciones es cada vez más baja y el electorado tiene la sensación de regalar su apoyo a una élite la cual no apostará por aquellas políticas destinadas al bien común. La incapacidad para incidir en la toma de decisiones y en la fiscalización de las políticas públicas resulta inexplicable para muchas personas jóvenes que, en pleno siglo XXI, disponen de todas las tecnologías, infraestructuras y formación. Los partidos políticos son vistos, por parte de este colectivo, como actores débiles frente al poder económico y existe la percep-

20 International Labour Force. Regional Report: National Events on Youth Employment in the Arab States / Youth Employment Programme. Disponible en: www.youthpolicy.org. 
ción que las decisiones se toman lejos de las sedes de los gobiernos democráticos y casi siempre para beneficiar a unos pocos. ${ }^{21}$ En el caso concreto de la región árabe, las elecciones son vistas como un mecanismo para atribuir a las redes tribales y familiares la capacidad para conservar el poder entre sus seguidores. En Europa, el paralelismo es menos evidente pero a la población les resulta relativamente fácil percibir los beneficiarios del poder surgido en las urnas, independientemente de su color político.

Otro foco de indignación presente en las movilizaciones es la aparente displicencia del sistema judicial para fiscalizar y castigar los casos de corrupción en las esferas políticas y empresariales. Un sistema que a ojos de la mayoría de la población se muestra incapaz de garantizar el cumplimiento de la legislación en beneficio de una minoría poderosa. La independencia judicial no solo es necesaria para mantener el equilibrio de poderes del estado, sino que es la última posibilidad de defensa de los más vulnerables. Si esta barrera se percibe como discreta y frágil, nadie puede extrañarse que la indignación tome formas tan contundentes. El Índice Mundial de Competitividad del Foro Económico Mundial ubicó tres países árabes - Líbano, Libia y Argelia - en el tercio superior a nivel mundial en falta de independencia judicial (Hammam, 2012).

Con diferencias muy significativas en cuanto a la intensidad, los países del norte y del sur del Mediterráneo han visto aumentar el papel de las fuerzas de orden público y, al mismo tiempo y como efecto opuesto, el rechazo creciente de la población hacia su policía. Si bien es cierto, como se ha mencionado anteriormente, que tradicionalmente los países de la región árabe han preservado el control social a través de la represión estatal, los intentos de ataque a la libertad de expresión y asociación han sido más motivados que nunca por los respectivos gobiernos.

Los dos principales retos que deben hacer frente las fuerzas gubernamentales de los estados árabes, el crecimiento demográfico y la entrada de las nuevas tecnologías, han incrementado el coste de la represión y los métodos tradicionales de control se han hecho menos efectivos. En Europa, si bien el control estatal no es tan férreo ni agresivo, y las acciones policiales en su mayoría no han resultado tan violentas, la contundencia con la que las fuerzas de seguridad han reprimido las manifestaciones ha subido algún grado respecto de períodos

21 «Juventud reformista». El País, 6 de mayo de 2014. 
anteriores. Pero más destacable que este aspecto, en Europa, ha sido la imagen criminalizada que ha recibido parte del colectivo joven contrario al actual sistema político y económico (Navarro, 2012). Manifestaciones de carácter absolutamente pacífico han finalizado con fuertes cargas policiales, muchas veces como respuesta a la provocación ante despliegues policiales desmesurados.

Sea como sea, las relaciones - habitualmente difíciles - entre las fuerzas de seguridad y la población se han ido deteriorando en los Estados del norte y sur del Mediterráneo. Se podrían señalar dos motivos: por un lado por la propia criminalización de parte de estos movimientos sociales - y en muchas ocasiones con la ayuda de medios de comunicación - y por otro la creencia que se atribuye a la policía de estar al servicio de la protección de los regímenes en lugar de la población (Malik y Awadallah, 2013).

Con todas las diferencias y la distancia que es necesario y prudente tener presente entre las dos situaciones, se han indicando situaciones análogas entre los países de los dos márgenes del Mediterráneo. Unas situaciones que han derivado en movimientos de revuelta y de deseo de cambio por parte de la población juvenil. ¿Tienen estas movilizaciones también objetivos similares?

Ambos movimientos de contestación buscan construir unas prácticas democráticas que permitan volver a empoderar a la población ante los respectivos gobiernos. Les motiva movilizarse debido a la nefasta situación económica, pero los objetivos son más amplios y pretenden cambiar - con mayor o menor medida - el sistema en general. Lo que se reivindica no es la reducción de la pobreza, sino el retorno de los mecanismos de control y decisión para reducirla y, en relación a este aspecto, se reclama particularmente a las élites políticas, por una parte, reducir su relación con los grandes poderes económicos para que dejen de marcar la agenda gubernamental, y por otra la implantación de mayor transparencia y buenas prácticas de las administraciones públicas. Al mismo tiempo se exige una independencia total del sistema judicial para que se apliquen sobre todos los poderes políticos y económicos los mismos procedimientos que el resto de la población.

Pero si existe una reivindicación clave en todas las movilizaciones que se han producido en los últimos años, es la que afecta al sistema electoral. No solo se reclamaba el derribo de los regímenes autoritarios en los Estados árabes correspondientes, el norte y el sur exigían procesos electorales abiertos, transparentes y competitivos. En particular en el sur de Europa, se demandaba poder disponer de meca- 
nismos reales para que los electores puedan incidir en la elección de sus candidatos, mayor proporcionalidad de los Parlamentos y la posibilidad de celebrar consultas refrendarías dentro de las legislaturas. En resumen, se reclamaba una democracia directa para romper con las dinámicas conservadoras de las élites políticas.

\section{DOS ENCUESTAS SOCIALES PARA EL MISMO ANÁLISIS}

Para llevar a cabo el análisis planteado en este artículo, se ha diseñado un modelo estadístico capaz de analizar, para un conjunto de países situados en ambas orillas del Mediterráneo, la existencia de factores compartidos, individuales y de país, económicos y sociales, que incidan en la confianza política de sus personas jóvenes. En dichos países, como se ha detallado, éstas han protagonizado importantes movilizaciones de protesta.

Este ejercicio ha sido posible a partir de dos de las mayores encuestas sociales internacionales, la ESS y la WVS, que han permitido el estudio planteado por diversos motivos. En ambas, las últimas oleadas se han presentado casi de forma simultánea en el tiempo y recogen el estado de opinión de las respectivas poblaciones justo en los momentos en que se celebraron las movilizaciones que sirven de contexto en el presente estudio (2012 y 2013 en el caso de la ESS, 2010 al 2013 en el caso de la WVS). ${ }^{22}$

Las dos encuestas se han realizado bajo un trabajo de campo similar, usando las entrevistas presenciales como método de recogida de la información (si bien es cierto que la WVS se reserva, además, la posibilidad de ejecutar entrevistas telefónicas en aquellos territorios más remotos), ${ }^{23}$ una y otra encuesta siguen un mismo sistema en la preparación y coordinación, en cada Estado existe una persona - vinculada al mundo académico - encargada de su ejecución y control, previo consenso del cuestionario por equipos internacionales, las dos encuestas recogen informaciones similares: condiciones laborales, confianza en las instituciones, valores, participación política o el consumo de los medios de comunicación, y finalmente, ambas encuestas permiten cru-

22 Es necesario advertir que el año en la toma de los datos muestrales puede depender, y depende, de la situación en los respectivos países. En algunos estados (por ejemplo Libia) los datos son recogidos en 2013, momento en que el país ostenta unas mínimas estructuras democráticas.

23 Disponible en: www.worldvaluessurvey.org. 
zar los resultados con una gran diversidad de variables sociodemográficas, además de la capacidad que muestran para realizar estudios longitudinales.

A pesar de estas ventajas, el uso comparativo de las dos encuestas presenta dos grandes inconvenientes. En primer lugar, la redacción de las preguntas puede confundir fácilmente la interpretación o incluso la propia intención de ésta y, en segundo lugar, las categorías de respuesta son distintas, motivo por el cual puede resultar inoperativo cualquier ejercicio comparativo. En este sentido, para una estricta adaptación al objetivo de este análisis, se han seleccionado las variables de las dos encuestas que se comparan en la tabla $1,{ }^{24}$ para la muestra de personas jóvenes de entre dieciséis y veintinueve años.

A pesar que la literatura académica no ha conseguido ponerse de acuerdo $^{25}$ en acotar de forma objetiva la franja de edad en que una persona puede considerarse metodológicamente joven, en este artículo se han utilizado dos criterios para la acotación: en primer lugar, ampliar la edad de las persona jóvenes hasta los veintinueve años para aumentar considerablemente el número de casos disponibles para el tratamiento estadístico y en segundo lugar, los años en que son recogidos los datos muestrales son posteriores a las fechas en que tuvieron

24 Más concretamente, la recodificación efectuada ha afectado a las variables de la siguiente manera:

- En cuanto al voto en las últimas elecciones se han reducido las categorías hasta obtener una variable dummie que recoge si se votó (1) o no (0), teniendo en cuenta sólo aquellos individuos mayores de 18 años.

- La confianza en el parlamento presentaba unas respuestas de diferente tipología: rn la ESS se preentaba una escala del 0 al 10, donde el 0 representaba la mínima confianza y el 10 la máxima y en la WVS se recogían 4 respuestas categóricas ordenadas de «muy de acuerdo» a «nada de acuerdo». Se ha recodificado la escala hasta reducirla a 4 categorías, manteniendo una distribución equitativa en la frecuencia de respuestas entre las dos variables.

- La situación laboral se ha recodificado en ambos casos para agrupar la diversidad de respuestas a tan solo seis: 1. Ocupado 2. Parado 3. Estudiante 4. Trabajos domésticos 5. Jubilado 6. Otros.

- Los niveles educativos se han equilibrado a partir del sistema de clasificación internacional ISCED.

25 «El de los 'ninis' es un buen ejemplo de individualización de los problemas sociales». Entrevista a Enrique Martín Criado para la revista Àmbits de Política i Societat del Colegio de Sociólogos y Politólogos de Cataluña. Disponible en: http://ambitscolpis.com. 
lugar las situaciones que motivaron las movilizaciones sociales, por lo que gran parte de sus protagonistas en el momento de realizar la encuesta ya sobrepasaban los veinticuatro o veinticinco años.

TABLA 1: VARIABLES SELECCIONADAS DE LA ENCUESTA SOCIAL EUROPA Y LA ENCUESTA MUNDIAL DE VALORES

\begin{tabular}{|l|c|c|l|}
\hline \multicolumn{1}{|c|}{$\begin{array}{c}\text { European Social Survey } \\
\text { (ESS) }\end{array}$} & Variables & Variables & \multicolumn{1}{|c|}{$\begin{array}{c}\text { Word Values Survey } \\
\text { (wVS) }\end{array}$} \\
\hline País & cntry & V2 & Código de país \\
\hline $\begin{array}{l}\text { Ha votado en las últimas } \\
\text { elecciones }\end{array}$ & vote & V227 & $\begin{array}{l}\text { Votar en las elecciones: } \\
\text { nivel Nacional }\end{array}$ \\
\hline Confianza en el parlamento & trstprl & V117 & $\begin{array}{l}\text { Confianza en el } \\
\text { parlamento }\end{array}$ \\
\hline $\begin{array}{l}\text { Actividad principal, últimos } \\
7 \text { días. } \\
\text { Todos los encuestados }\end{array}$ & mnactic & V229 & Situación laboral \\
\hline $\begin{array}{l}\text { El nivel más alto de } \\
\text { educación alcanzado }\end{array}$ & edulvid & V248 & $\begin{array}{l}\text { El nivel más alto de } \\
\text { educación alcanzado }\end{array}$ \\
\hline Edad & agea & V242 & Edad \\
\hline Género & gndr & V240 & Género \\
\hline
\end{tabular}

Fuente: elaboración propia.

En cuanto a los países, se han seleccionado la mayoría de Estados de los límites sur, este y norte del Mediterráneo. Sin embargo, no se han encontrado datos para Siria y pese a que la ESS es una encuesta circunscrita al ámbito territorial europeo, numerosos países del sur del continente no han sido recogidos por la misma, siendo la omisión de Grecia el caso más paradójico.

Por otra parte, también se ha considerado una muestra de estados del centro y norte del continente europeo como actores de control sobre los estados del sur, para comprobar la certeza estadística de las diferencias y similitudes que se obtengan. En concreto, este grupo de control está formado por los estados del centro y norte del continente europeo que representan cada una de las tipologías de Estado del bienestar según la clasificación tradicional de Esping-Andersen (2009); es decir, el continental, el anglosajón y el nórdico.

Siguiendo todos estos criterios la muestra final de estados seleccionados para el análisis es la siguiente: Albania, Alemania, Argelia, Bélgica, Dinamarca, Egipto, Eslovenia, España, Finlandia, Francia, Irlanda, Israel, Italia, Jordania, Kosovo, Líbano, Libia, Marruecos, Noruega, Países Bajos, Portugal, Reino Unido, República Checa, Suecia, Túnez, Turquía y Chipre. 


\section{a) Confianza en el sistema político}

Antes de iniciar el estudio de los factores que inciden en la confianza de las personas jóvenes en los países considerados y por tanto factores que han podido influir en las movilizaciones juveniles, se plantean dos preguntas: ¿cuál es la confianza media de los Estados objeto de estudio hacia su Parlamento nacional? ¿Cuál es la distribución territorial de estas medias?

Para responder a ambas preguntas se realiza un estudio comparativo de los valores de la variable confianza parlamentaria de las personas jóvenes obtenidos para cada uno de los Estados objeto de estudio, mediante el cálculo del rango intercuartílico ${ }^{26}$ de dicha variable, como puede observarse en la figura 1 .

\section{FIGURA 1: RANGO INTERCUARTÍLICO DE LA VARIABLE CONFIANZA PARLAMENTARIA POR PAÍSES}

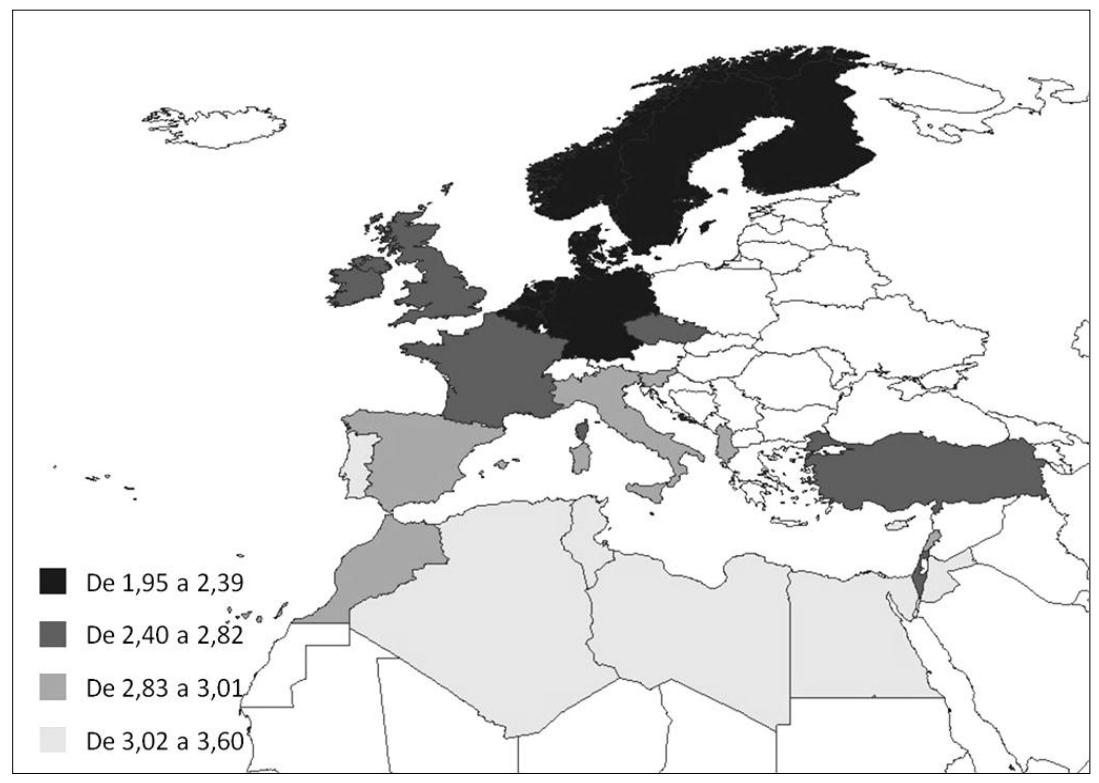

Fuente: elaboración propia.

26 Sin embargo, mediante cualquier otra técnica de agrupación o clústering se obtienen unos resultados prácticamente idénticos. 
Según estos resultados se observan cuatro grupos de estados: aquellos que presentan una mayor confianza hacia su Parlamento siguiendo un orden alfabético: Alemania, Bélgica, Dinamarca, Finlandia, Noruega, Países Bajos y Suecia. Otro grupo formado por Francia, Irlanda, Israel, Reino Unido, República Checa y Turquía, y de los últimos dos grupos con más desconfianza parlamentaria, uno formado por: Albania, Eslovenia, España, Italia, Líbano y Marruecos, y el último por: Argelia, Egipto, Jordania, Libia, Portugal, Túnez y Chipre.

A partir de la representación cartográfica se puede observar una relación territorial de la variable confianza en el parlamento: una región nórdica en la que se añadirían Alemania, Bélgica y Países Bajos con un alto grado de confianza y a su vez con un nivel de ingreso alto (US\$57.603 a precios actuales de PIB per cápita), ${ }^{27}$ y una región mixta entre la Europa continental, los Estados anglosajones y Turquía e Israel (con unas idiosincrasias particulares y diferenciadas de su vecindad) con una confianza ligeramente menor y un nivel de ingreso medio (US\$31.596 a precios actuales de PIB per cápita). El resto de Estados situados en las dos orillas del Mediterráneo o, mejor dicho, en el sur de Europa (US\$17.248 a precios actuales de PIB per cápita) y el sur y este del Mediterráneo (US\$11.110 a precios actuales de PIB per cápita), son los que centran la atención del estudio.

Una vez comprobada esta relación se efectúa una regresión multinivel para establecer la causalidad entre dicha variable, y otras de carácter individual y de país, con el fin de determinar las características que mejor explican las diferencias entre países para comprender el grado de confianza parlamentaria de la juventud, teniendo en cuenta un conjunto de características de los individuos que forman parte de cada Estado y del propio al que pertenecen.

\section{b) Factores multinivel que inciden en la confianza en el sistema político de las personas jóvenes}

Para llevar a cabo el análisis multinivel, se definen las variables que se incorporan en el modelo:

27 Valores agregados de PIB per cápita (US\$ a precios actuales calculados a partir de los datos facilitados por el Banco Mundial).

Disponible en: http://datos.bancomundial.org. 
- Como variable dependiente: confianza en el parlamento que toma valores positivos (mayor confianza) en el 1 y los más negativos (menos confianza) en el 4, manteniendo intacto el sentido de interpretación de las respuestas procedentes de las dos encuestas ESS y la WVS.

- Como variables individuales: sexo del entrevistado; edad (de 16 a 24 años); participación en las últimas elecciones nacionales; nivel de educación (creciente).

- Como variables dummy: si la persona joven está ocupada, parada (desempleada) o es estudiante. ${ }^{28}$

- Como variables de grupo: además del propio Estado que actúa como variable identificadora, se considera el nivel medio de educación del país (entendiendo éste como el porcentaje de población con estudios terciarios según clasificación ISCED), ${ }^{29}$ el porcentaje de paro juvenil del conjunto de la población joven de 16 a 24 años y el índice Gini de desigualdad social. ${ }^{30}$

Como paso preliminar, se calcula la significación estadística del efecto país, sin otra información añadida. El resultado del modelo nulo, que se muestra en la tabla 2 , indica que al menos un $21 \%^{31}$ de la variación de la confianza en el parlamento de las personas jóvenes se debe a algún o algunos fenómenos que tienen que ver con las características globales del Estado. ${ }^{32}$

28 Se considera a la persona ocupada si en la Encuesta Social Europea declara que su principal actividad en los últimos 7 días (variable mnactic) es el trabajo remunerado, o bien en la Encuesta Mundial de Valores (variable v229) declara que su situación laboral es de trabajo a tiempo completo, parcial o bien auto empleado. Por su parte, se considera a la persona desempleada si en la ESE manifiesta estar desempleada ya sea buscando trabajo o no; y para la WVS si está desempleada.

29 Véase: http://epp.eurostat.ec.europa.eu.

30 Según definición del Banco Mundial, el índice de Gini mide hasta qué punto la distribución del ingreso (o, en algunos casos, el gasto de consumo) entre individuos u hogares dentro de una economía se aleja de una distribución perfectamente equitativa.

31 Porcentaje de variación de la variable dependiente: intercepto / ((intercepto + residuo $))=0.2109$.

32 Una afirmación, ésta, corroborada por todas las pruebas de significación y fiabilidad estadística apropiadas (estimación de coeficiente de correlación intra-clase, estimador de máxima probabilidad -REML-, y análisis de varianza) y no adjuntadas en estos resultados. 
TABLA 2: INTERCEPTO Y RESIDUO MODELO NULO

\begin{tabular}{|c|c|c|}
\hline & VARIANCE & STDDEV \\
\hline (Intercept) & 0.1919474 & 0.4381180 \\
\hline Residual & 0.7179097 & 0.8472955 \\
\hline
\end{tabular}

A continuación, se añaden los predictores de carácter individual considerando la influencia de los diferentes grupos de países, como se observa en la tabla 3 .

TABLA 3: MODELO CON PREDICTORES INDIVIDUALES (MODELO 1)

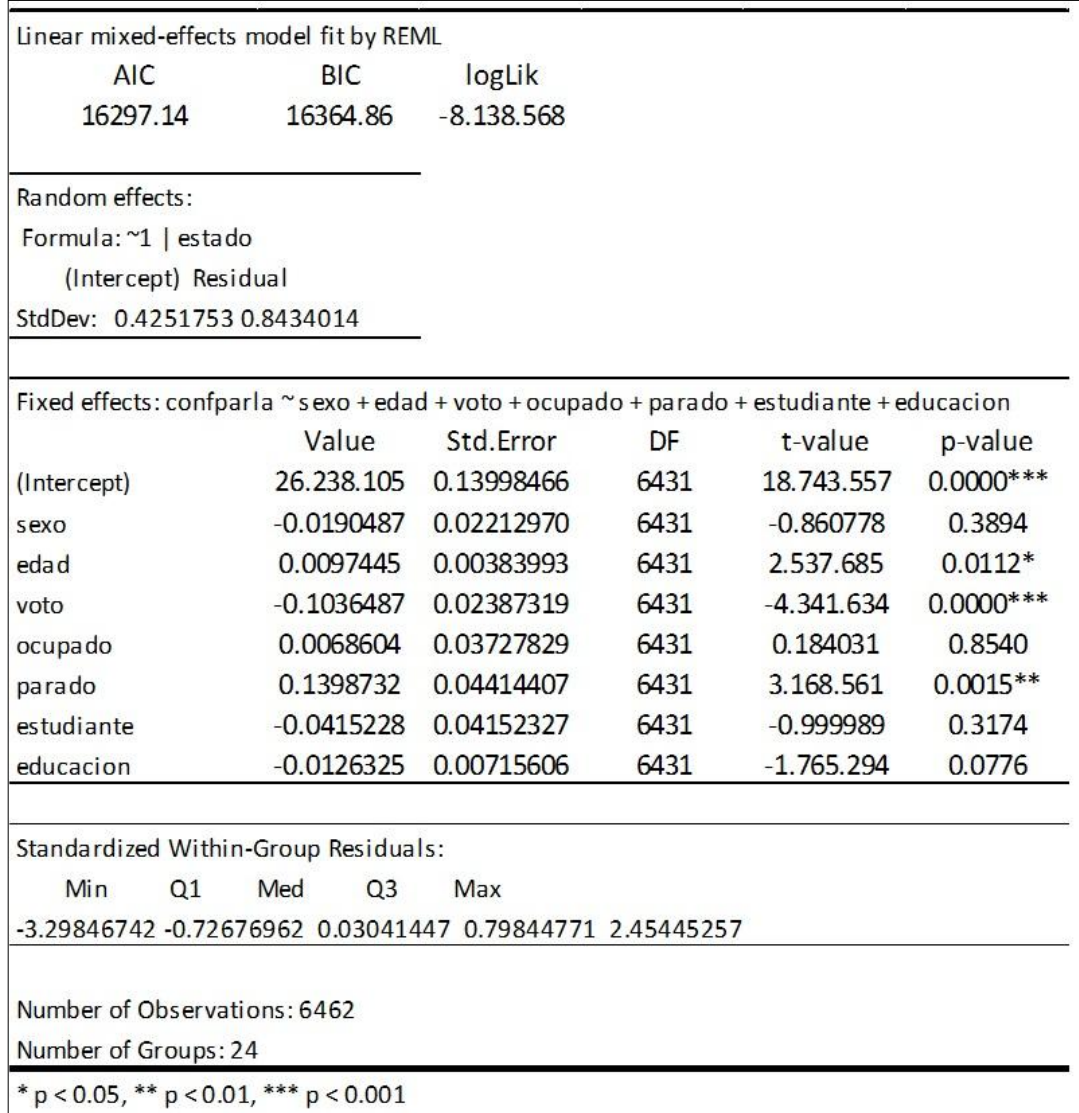




\begin{tabular}{|c|c|c|}
\hline & VARIANCE & STDDEV \\
\hline (Intercept) & 0.18077400 & 0.4251750 \\
\hline Residual & 0.71132590 & 0.8434010 \\
\hline
\end{tabular}

De dichos resultados se deduce que el sexo del entrevistado no parece tener influencia para explicar la confianza en el parlamento, todo lo contrario que sucede con la edad, mayor desconfianza a medida que aumenta la edad de la persona joven. ${ }^{33}$ Por su parte, haber votado en las últimas elecciones también es significativo, de modo que la participación electoral está relacionada con una mayor confianza hacia la institución votada. En cuanto a la situación laboral, se observa que solo presenta influencia estadística inversa el hecho de estar parado; es decir, influye negativamente sobre la confianza en el sistema político. Finalmente, también se deduce que a mayor nivel educativo, menor es la desconfianza hacia el Parlamento.

Sin embargo, a pesar de la coherencia de los resultados, el modelo con los predictores individuales solo es capaz de explicar un $0,9 \%{ }^{34}$ de la variación del nivel de confianza a través de los diferentes Estados. Las diferencias en las características individuales de las personas jóvenes de los países estudiados, explicarían en muy poca medida la confianza hacia los respectivos Parlamentos.

Prosiguiendo en el análisis, se añaden aquellas variables de grupo que en modelos preliminares se han manifestado más robustas estadísticamente y han creado menos problemas de colinealidad entre ellas y cuyos resultados se presentan a continuación en la tabla 4.

33 En este sentido, este no es un dato que nos interese excesivamente, ya que al limitar el análisis a la población juvenil sólo observamos el comportamiento dentro de este colectivo y no en relación a la población adulta.

34 Porcentaje de variación de la variable dependiente: 1- (residuo modelo con predictore/residuo modelo nulo) $=0.0092$. 
TABLA 4: MODELO CON PREDICTORES INDIVIDUALES Y DE GRUPO (MODELO 2)

\begin{tabular}{|c|c|c|}
\hline \multicolumn{3}{|c|}{ Linear mixed-effects model fit by REML } \\
\hline $\mathrm{AIC}$ & $\mathrm{BIC}$ & logLik \\
\hline 16299.36 & 16387.4 & -8136.68 \\
\hline \multicolumn{3}{|c|}{ Random effects: } \\
\hline \multicolumn{3}{|c|}{ Formula: 1 | estado } \\
\hline & (Intercept) & Residual \\
\hline StdDev: & 0.2321474 & 0.8434105 \\
\hline
\end{tabular}

Fixed effects: confparla sexo + edad + voto + ocupado + parado + estudiante + educacion + Niv_ed + Paro_juv + gini

\begin{tabular}{lccccc} 
& Value & Std.Error & DF & t-value & p-value \\
(Intercept) & 18.648 .428 & 0.4806177 & 6431 & 3.880 .096 & $0.0001^{* * *}$ \\
sexo & -0.0194336 & 0.0221257 & 6431 & -0.878328 & 0.3798 \\
edad & 0.0098120 & 0.0038379 & 6431 & 2.556 .605 & $0.0106^{*}$ \\
voto & -0.1058726 & 0.0238438 & 6431 & -4.440 .254 & $0.0000^{* * *}$ \\
ocupado & 0.0064133 & 0.0372411 & 6431 & 0.172209 & 0.8633 \\
parado & 0.1390731 & 0.0441081 & 6431 & 3.153 .009 & $0.0016^{* *}$ \\
estudiante & -0.0414389 & 0.0414690 & 6431 & -0.999275 & 0.3177 \\
educacion & -0.0107967 & 0.0071503 & 6431 & -1.509 .966 & 0.1311 \\
Niv_ed & -0.0088542 & 0.0028986 & 20 & -3.054 .645 & $0.0063^{* *}$ \\
Paro_juv & 0.0176549 & 0.0049378 & 20 & 3.575 .467 & $0.0019^{* *}$ \\
gini & 0.0265378 & 0.0115450 & 20 & 2.298 .634 & $0.0324^{*}$ \\
\hline
\end{tabular}

Standardized Within-Group Residuals:

$\begin{array}{lllll}\text { Min } & \text { Q1 } & \text { Med } & \text { Q3 } & \text { Max }\end{array}$

$\begin{array}{lllll}-330.318 .110 & -0.72353456 & 0.02987119 & 0.80489202 & 245.812 .425\end{array}$

Number of Observations: 6462

Number of Groups: 24

${ }^{*} \mathrm{p}<0.05,{ }^{* *} \mathrm{p}<0.01,{ }^{* * *} \mathrm{p}<0.001$

\begin{tabular}{|c|c|c|}
\hline & VARIANCE & STDDEV \\
\hline (Intercept) & 0.05389242 & 0.2321470 \\
\hline Residual & 0.71134120 & 0.8434100 \\
\hline
\end{tabular}


El resultado del nuevo análisis, que incorpora los predictores de segundo nivel (de país) indica que las variables individuales siguen teniendo la misma influencia y en el mismo sentido que en el modelo anterior, a excepción del nivel educativo que pierde significación. Por su parte, las tres variables grupales son significativas estadísticamente: el nivel educativo medio de la población está relacionado con la confianza en un sentido directamente proporcional y en cambio, el paro juvenil y el índice de Gini lo son en un sentido inverso; es decir, a más paro y más desigualdad en el reparto de la riqueza, menor confianza. $Y$ en cuanto a la capacidad explicativa, este nuevo modelo que incorpora las variables de país, mejora considerablemente con una variación de la confianza del $71,9 \%{ }^{35}$

Hasta el momento se ha supuesto un comportamiento fijo de las variables individuales en todos los Estados; es decir, que la influencia de haber participado en las elecciones, estar parado o tener mayor nivel educativo tuviera el mismo efecto sobre la confianza en el parlamento con independencia del país analizado. Esta premisa es claramente cuestionable y por este motivo, en los gráficos 4 a 7 se analiza la relación entre las diversas variables individuales y la variable dependiente para cada uno de los países analizados.

35 Porcentaje de variación de la variable dependiente: 1- (residuo modelo con predictore/residuo modelo nulo) $=0.7196$. 
GRÁFICO 4: DESCONFIANZA EN EL PARLAMENTO VS EDAD, POR PAÍSES

\begin{tabular}{|c|c|c|c|c|c|c|c|c|}
\hline \multirow{23}{*}{ 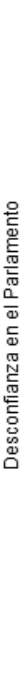 } & & & $\begin{array}{cc}20 & 25 \\
1 & 1\end{array}$ & & $20 \quad 25$ & & 20 & \\
\hline & & $\mathrm{NO}$ & PT & SE & SI & TN & TR & \\
\hline & & & 0000000000 & 000000000 & 0000000000000 & 000000000000 & 000000000000 & 4.0 \\
\hline & & 0000000000000 & 0000000000 & 000000000000 & o-0aمaمo0090000 & 000000000000 & 000000000000 & 3.0 \\
\hline & & 00000000000000 & 000000000 & 000 Q & 00000000000000 & $00 \quad 0000000$ & 000000000000 & $\begin{array}{l}2.5 \\
2.0\end{array}$ \\
\hline & & 00000000000000 & 000 & $0 \quad 000000000000$ & 0000 & $\begin{array}{lllll}0 & 0 & 000 & 0 & 0\end{array}$ & 000000000000 & $\begin{array}{l}1.5 \\
1.0\end{array}$ \\
\hline & & \begin{tabular}{|c|}
$\mathrm{IE}$ \\
\end{tabular} & IL & IT & $\mathrm{JO}$ & MA & $\mathrm{NL}$ & \\
\hline & 4.0 & 0000000000000 & . 000000000000 & 00000000000000 & 000000000000 & 00000000000 & 00000000 & \\
\hline & $\begin{array}{l}3.5 \\
3.0\end{array}$ & -00000000000000 & 0000000000000 & 00000000000000 & -000000000000 & |معمصم000000000 & 000000000000 & \\
\hline & $\begin{array}{l}2.5 \\
2.0\end{array}$ & -00000000000000 & 00000000000000 & 0000000000000 & 000000000000 & 000000000000 & -00000000000000 & - \\
\hline & $\begin{array}{l}1.5 \\
1.0\end{array}$ & $0000 \quad 00000$ & $0 \quad 0000000000000$ & $0 \quad 000 \quad 0$ & 0000000000 & 000000000000 & $0 \quad 00000000000$ & \\
\hline & & $\mathrm{DZ}$ & $E G$ & ES & $\mathrm{FI}$ & FR & GB & \\
\hline & & 000000000000 & 000000000000 & 000000000000 & 0000000 & 00000000000 & 000000000000 & -4.0 \\
\hline & & 000000000000 & 0000000000000 & 00000000000000 & 00000000000 & $0000000 \quad 000000$ & 0.000000000000 & 3.0 \\
\hline & & 000000000000 & 000000000000 & 00000000000000 & —-000000000ण & 0000000000000 & 00000000000000 & {$\left[\begin{array}{l}2.0 \\
-2.0\end{array}\right.$} \\
\hline & & 00000000 & 0000000000 & 00000 & 0000000000 & $0 \quad 000 \quad 00$ & 00000000 & $\begin{array}{l}1.5 \\
-1.0\end{array}$ \\
\hline & & & $\mathrm{BE}$ & CY & $\mathrm{CZ}$ & $\mathrm{DE}$ & DK & \\
\hline & 4.0 & 000000000 & 000000 & 00000000000000 & 0000000000 & 000000000 & 000000 & \\
\hline & 3.0 & 000000000 & 0000000000 & $0-000000000000$ & 000000000 & 000000000000 & 00000000000 & \\
\hline & $\begin{array}{l}2.5 \\
2.0\end{array}$ & $0000000 \%$ & 0000000000 & $00000 \quad 000 \quad 0000$ & 000000000 & 000000000000 & |00000000000000 & \\
\hline & $\begin{array}{l}1.5 \\
1.0\end{array}$ & 00000000 & 0000000000 & 00000 & 0000 of & 00000 & $00 \quad 00000000000$ & \\
\hline & & 25 & & $20 \quad 25$ & & 20 & & \\
\hline & & & & & & & & \\
\hline
\end{tabular}

GRÁFICO 5: DESCONFIANZA EN EL PARLAMENTO VS VOTO, POR PAÍSES

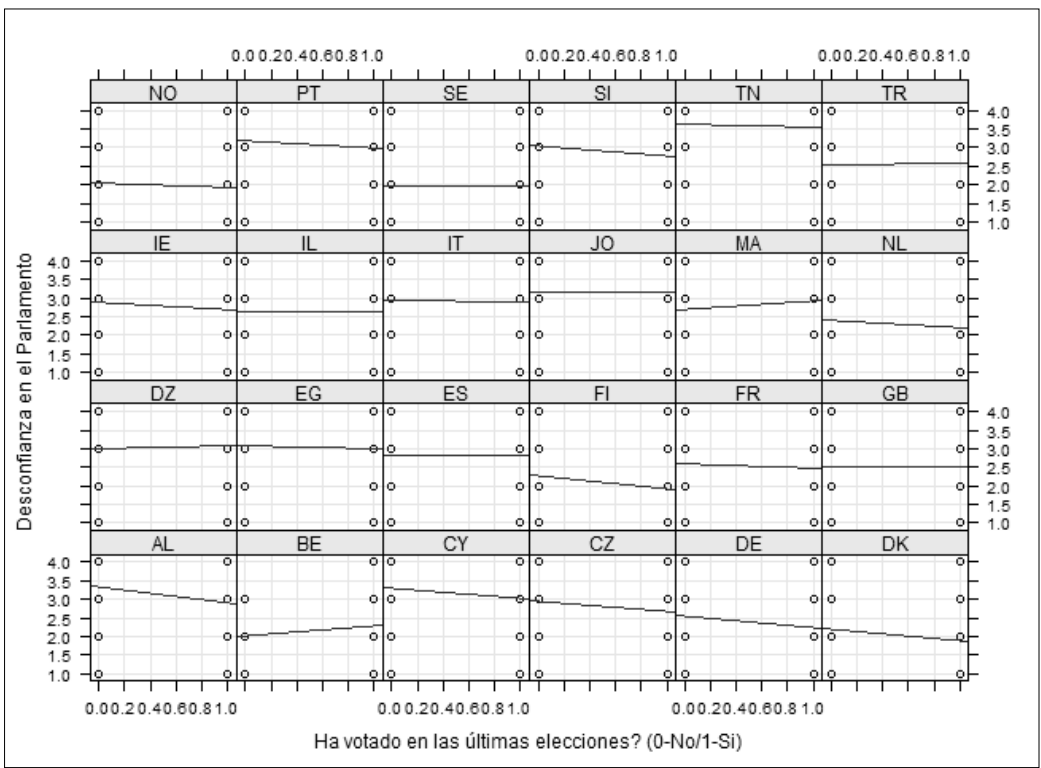


GRÁFICO 6: DESCONFIANZA EN EL PARLAMENTO VS DESEMPLEO, POR PAÍSES

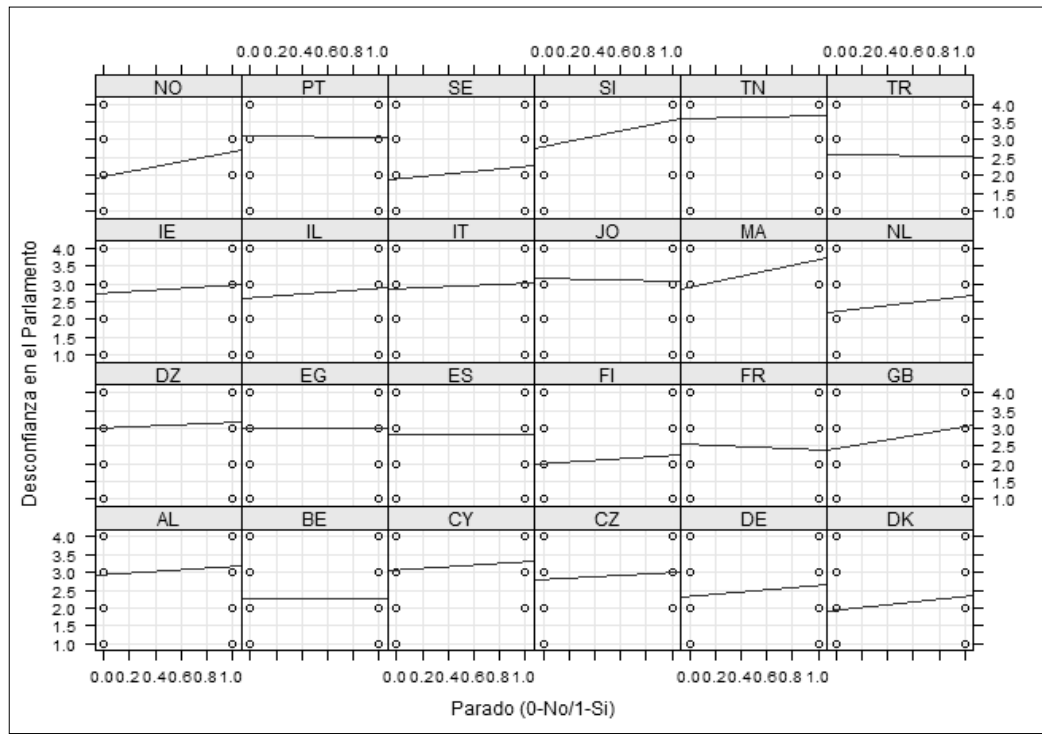

GRÁFICO 7: DESCONFIANZA EN EL PARLAMENTO VS NIVEL EDUCATIVO, POR PAÍSES

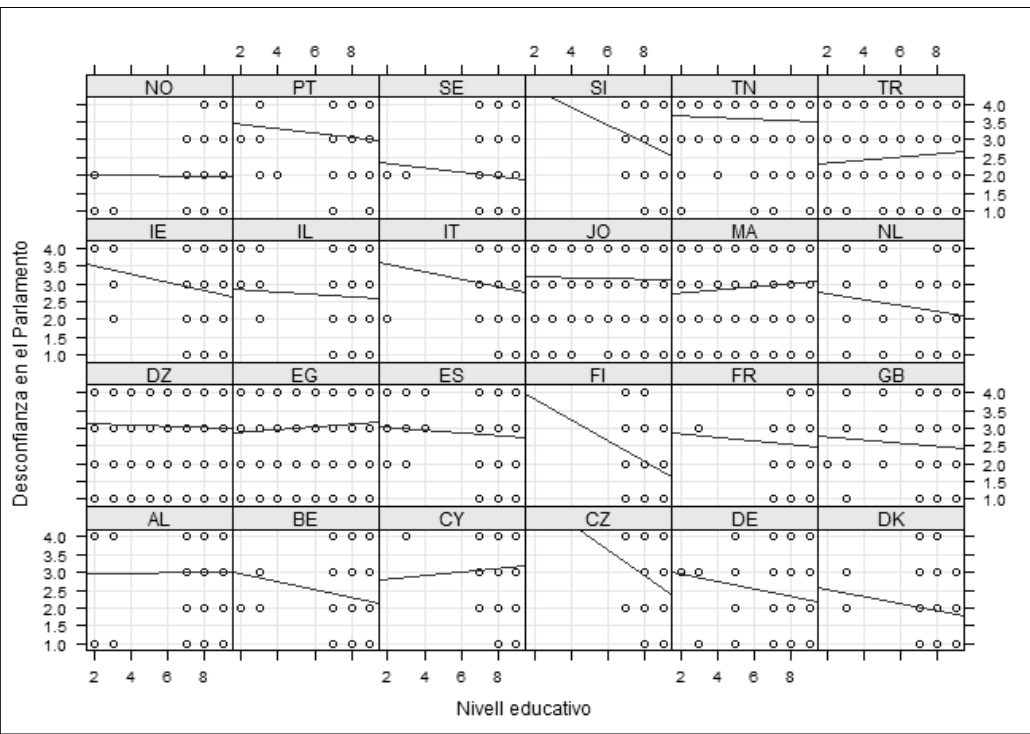


Los gráficos muestran que el nivel educativo individual es el factor que presenta una mayor dependencia del país en que se toman los datos. ${ }^{36}$ Por ello, se estima un nuevo modelo con efectos aleatorios en la variable educación, cuyos resultados se muestran en la tabla 5. Se observa como la variable educación es explicativa, así como, edad, voto, parado, nivel educativo, paro juvenil e índice de Gini.

\section{TABLA 5: MODELO CON PREDICTORES INDIVIDUALES Y DE GRUPO, CON EFECTOS ALEATORIOS EN EDUCACIÓN (MODELO 3)}

\begin{tabular}{|c|c|c|c|c|c|}
\hline \multicolumn{6}{|c|}{ Linear mixed-effects model fit by REML } \\
\hline AIC & BIC & logLik & & & \\
\hline 16290.07 & 16391.65 & -8.130 .033 & & & \\
\hline \multicolumn{6}{|c|}{ Random effects: } \\
\hline \multicolumn{6}{|c|}{ Formula: educacion | estado } \\
\hline \multicolumn{6}{|c|}{ Structure: General positive-definite, Log-Cholesky parametrization } \\
\hline & StdDev & Corr & & & \\
\hline (Intercept) & 0.55842056 & (Intr) & & & \\
\hline educacion & 0.04939129 & -0.931 & & & \\
\hline Residual & 0.84123125 & & & & \\
\hline \multicolumn{6}{|c|}{$\begin{array}{l}\text { Fixed effects: confparla } \sim \text { sexe }+ \text { edat }+ \text { vot }+ \text { ocupat }+ \text { aturat }+ \text { estudiant }+ \\
\text { educacio }+ \text { Niv_ed }+ \text { Atur_juv }+ \text { gini }\end{array}$} \\
\hline & Value & Std. Error & DF & t-value & p-value \\
\hline (Intercept) & 21.127 .732 & 0.4722785 & 6431 & 4.473 .575 & $0.0000 * * *$ \\
\hline sexo & -0.0142336 & 0.0221113 & 6431 & -0.643728 & 0.5198 \\
\hline edad & 0.0114021 & 0.0038532 & 6431 & 2.959 .159 & $0.0031 * *$ \\
\hline voto & -0.0899497 & 0.0240405 & 6431 & -3.741 .598 & $0.0002 * * *$ \\
\hline ocupado & 0.0046702 & 0.0373285 & 6431 & 0.125110 & 0.9004 \\
\hline parado & 0.1307289 & 0.0442144 & 6431 & 2.956 .704 & $0.0031 * *$ \\
\hline estudiante & -0.0437422 & 0.0414459 & 6431 & -1.055 .405 & 0.2913 \\
\hline educacion & -0.0376582 & 0.0139098 & 6431 & -2.707 .310 & $0.0068 * *$ \\
\hline Niv_ed & -0.0125559 & 0.0027913 & 20 & -4.498 .177 & $0.0002 * * *$ \\
\hline Paro_juv & 0.0167593 & 0.0047177 & 20 & 3.552 .469 & $0.0020 * *$ \\
\hline gini & 0.0318037 & 0.0110631 & 20 & 2.874 .746 & $0.0094 * *$ \\
\hline \multicolumn{6}{|c|}{ Standardized Within-Group Residuals: } \\
\hline Min & Q1 & Med & Q3 & Max & \\
\hline-329.011 .541 & -0.72780577 & 0.03307853 & 0.79340727 & 247.453 .805 & \\
\hline \multicolumn{6}{|c|}{ Number of Observations: 6462} \\
\hline \multicolumn{6}{|c|}{ Number of Groups: 24} \\
\hline$* \mathrm{p}<0.05, * *$ & $<0.01, * * * \mathrm{p}$ & 0.001 & & & \\
\hline
\end{tabular}

36 Afirmación, esta, confirmada por análisis de correlación de Kendall tau para el primer y cuarto gráfico y biserial para el segundo y tercero no adjuntados en estas páginas. 
Mediante un análisis de la variancia (ANOVA), tabla 6, se concluye que ambos modelos 2 y 3 , es decir con efectos fijos y con efectos aleatorios, son significativos.

TABLA 6: ANOVA MODELO 2 VS MODELO 3

\begin{tabular}{|c|c|c|c|c|c|c|c|c|}
\hline & MODEL & DF & AIC & BIC & LOGLIK & TEST & L. RATIO & P-VALUE \\
\hline $\begin{array}{c}\text { Modelo } \\
2\end{array}$ & 1 & 15 & 16290.07 & 16391.65 & -8.130 .033 & & & \\
\hline $\begin{array}{c}\text { Modelo } \\
3\end{array}$ & 2 & 13 & 16299.36 & 16387.40 & -8.136 .680 & 1 vs 2 & 1.329 .415 & 0.0013 \\
\hline
\end{tabular}

De este resultado se infiere que el nivel educativo individual influye significativamente sobre la confianza parlamentaria, incluso teniendo en cuenta los efectos propios en cada uno de los países considerados.

Avanzando en el estudio, se considera la posibilidad de interacción entre el nivel de educación individual y la desigualdad económica de un país. En este sentido, cabria esperar que a mayor desigualdad económica mayor sea la importancia que juega el nivel educativo para entender el posicionamiento individual en la desconfianza institucional. Para probar dicha hipótesis se incluye en el modelo anterior (modelo 3) una nueva variable que identifica la relación entre el nivel educativo (variable individual) con el índice de Gini (variable grupal), obteniendo los resultados que se presentan a continuación en la tabla 7.

TABLA 7: MODELO FINAL (MODELO 4)

\begin{tabular}{|c|c|c|c|c|c|}
\hline (Intercept) & $\begin{array}{l}\text { Value } \\
4.440\end{array}$ & $\begin{array}{c}\text { Std.Error } \\
0.958\end{array}$ & $\begin{array}{l}\text { DF } \\
6430\end{array}$ & $\begin{array}{r}\text { t-value } \\
4.635\end{array}$ & $\begin{array}{l}\text { p-value } \\
0.000^{\star * *}\end{array}$ \\
\hline sexo & -0.014 & 0.022 & 6430 & -0.649 & 0.516 \\
\hline edad & 0.012 & 0.004 & 6430 & 3.084 & $0.002^{* *}$ \\
\hline voto & -0.086 & 0.024 & 6430 & -3.590 & $0.000^{\star * *}$ \\
\hline ocupado & 0.005 & 0.037 & 6430 & 0.138 & 0.890 \\
\hline parado & 0.131 & 0.044 & 6430 & 2.966 & $0.003^{* *}$ \\
\hline estudiante & -0.046 & 0.041 & 6430 & -1.104 & 0.270 \\
\hline educacion & -0.282 & 0.090 & 6430 & -3.140 & $0.002^{* *}$ \\
\hline Niv_ed & -0.013 & 0.003 & 20 & -5.010 & $0.000 * * *$ \\
\hline Paro_juv & 0.017 & 0.005 & 20 & 3.759 & $0.000^{* * *}$ \\
\hline gini & -0.036 & 0.027 & 20 & -1.331 & 0.198 \\
\hline educacion:gini & 0.007 & 0.003 & 6430 & 2.786 & $0.005^{\star *}$ \\
\hline
\end{tabular}


La hipotética relación entre nivel educativo que ha alcanzado una persona joven y el índice de Gini, como medida de desigualdad de un país, para explicar el grado de confianza en el parlamento de su país se demuestra estadísticamente significativa. ${ }^{37}$ Estos resultados avalarían el objeto de este artículo, como se detalla en el siguiente apartado de conclusiones.

\section{CONCLUSIONES}

A lo largo de este artículo se ha puesto de manifiesto que, junto a la actual crisis económica, la desconfianza de las personas jóvenes hacia el sistema político e institucional ha alcanzado niveles preocupantes, muy especialmente en los países del sur de Europa, que son a su vez los que poseen las mayores tasas de desempleo juvenil. Al mismo tiempo, los países del sur del Mediterráneo han visto surgir movimientos de protesta, también protagonizados mayoritariamente por personas jóvenes, como respuesta a una grave situación de desempleo combinada con la inacción de los respectivos gobiernos, muchos de ellos Estados autocráticos. Muestra de esta situación son los movimientos de protesta conocidos como la «primavera árabe» y los «indignados» en España. A pesar de las diferencias socioeconómicas, educativas y laborales de ambas zonas — que no son objeto de este estudio-, se han analizado algunos factores que han podido incentivar estas movilizaciones.

En este contexto, se ha pretendido analizar a partir de una muestra de población joven, movilizada o no, procedente de diversos Estados de la cuenca del Mediterráneo, qué factores pueden influir en su confianza hacia sus instituciones políticas. Para ello se ha procedido a explotar dos encuestas de referencia, la Encuesta Social Europea (ESS) y la Encuesta Mundial de Valores (WVS), seleccionando un conjunto de variables comparables.

Se ha constatado un bajo nivel de confianza de las personas jóvenes hacia los respectivos parlamentos nacionales, entendidos como instituciones políticas de referencia y un análisis de clasificación ha permitido delimitar cuatro zonas geográficas que agrupan diversos países con tasas de desconfianza política similares: los Estados del norte del continente europeo con las tasas más bajas, los Estados del

37 Cabe señalar que según los datos facilitados por el Banco Mundial, los países objeto de estudio con mayor tasa de paro juvenil, a su vez presentan elevados valores del índice de Gini. 
centro de Europa juntamente con los países anglosajones, y en la escala alta de desconfianza, los Estados del Mediterráneo situados en ambas orillas. También se ha comprobado que las personas jóvenes de los países del norte y del sur del Mediterráneo comparten una situación de desconfianza institucional similar, mientras que ésta difiere considerablemente entre personas jóvenes de países del norte y del sur del continente europeo.

Mediante técnicas de regresión multinivel, se ha verificado que las características individuales de las personas jóvenes objeto de estudio - sexo, edad, si ha votado, situación laboral y nivel educativo alcanzado- explican en poca medida las diferencias entre países en comparación con las características grupales de estos Estados. Es decir, la desconfianza se explica, sobre todo, por variables socioestructurales - desempleo juvenil, desigualdad en la distribución de la riqueza, sistemas políticos autoritarios, etcétera- más que por las características de los individuos, puesto que resultan estadísticamente significativos el nivel educativo medio del país, su tasa de paro y el nivel de desigualdad. No obstante, el nivel educativo es la variable individual con mayor capacidad explicativa de la confianza política.

Finalmente, se ha considerado una posible interacción entre el nivel educativo individual y el grado de desigualdad económica del país y los resultados no solo confirman su relación, sino que también indican que la relación entre nivel educativo y confianza institucional es más robusta a medida que aumenta la desigualdad económica. Bajo este supuesto, en aquellos países con mayor desigualdad, es mayor la diferencia en el grado de desconfianza política entre las personas jóvenes con elevados niveles educativos respecto los que no poseen educación. Por el contrario, en países con menor desigualdad, la diferencia en la confianza política de las personas jóvenes disminuye antes distintos niveles de educación alcanzado por éstos. El modelo resultante también indica la capacidad explicativa de la situación de desempleo de la persona joven para entender posicionamientos de mayor desconfianza, y la relación, quizás redundante, entre el hecho de haber participado en las últimas elecciones y presentar una mayor propensión a la confianza institucional.

¿Sugieren estos resultados que un mayor nivel educativo conllevaría una mayor confianza de las personas jóvenes hacia sus instituciones, representadas en este caso por su Parlamento Nacional? La respuesta parece ser afirmativa especialmente cuando esta relación interactúa con el grado de desigualdad económica del país. Por consiguiente, en socie- 
dades más igualitarias - como los Estados del centro y norte de Euro$\mathrm{pa}$ - la valoración de las personas jóvenes hacia las instituciones puede depender de otros factores distintos al nivel de educación alcanzada.

Sumando y sintetizando estos tres elementos, bajo nivel educativo, desempleo y posición abstencionista, permite dibujar el triple perfil de desafección política de las personas jóvenes en los países objeto de estudio, de ambas orillas del Mediterráneo. Un análisis — con enfoques de investigación más cualitativos - centrado en los movimientos sociales impulsores de las principales movilizaciones de protesta política como se ha relatado en estas páginas, ayudaría a complementar esta fotografía.

BARCELONA (ESPAÑA), OCTUBRE 2014

RECIBIDO: OCTUBRE 2014 ACEPTADO: NOVIEMBRE 2014 


\section{REFERENCIAS BIBLIOGRÁFICAS}

Abebe, Tatel y Anne Trine Kuorholt (2012): Young People, Participation, and Sustainable Development in an Urbanizing World. Nairobi: United Nations Human Settlement Programme (UN-Habitat).

CAMPRUBI, ANDREU (2013): Una mirada general a l'atur juvenil. Repensant el concepte de treball. Quines ocupacions per quins joves? Trobar feina o crear Feina? Barcelona: IGOP.

Esping Andersen, G. (1999): Social Foundations of Postindustrial Economies. Oxford: Oxford University Press.

FERnÁnDEZ-Planells, A.; C. FeiXA y M. Figueras (2013): «El 15M en España: diferencias y similitudes en las prácticas comunicativas con los movimientos previos». Última Década N³9. Valparaíso: Ediciones CIDPA.

- (2014): «Communication Among Young People in the \#spanishrevolution. Uses of the Online-offline Tools to Obtain Information in the \#acampadabcn». New Media \& Society, 16(3).

FONDO MONETARIO INTERNACIONAL (2014): Perspectivas de la economía mundial (Informe WEO).

HAMmAM, MONA et al. (2011): «Employment, Social Protection and Fiscal Policy». En: Arab Development Challenges Report 2011: Towards the Developmental State in the Arab Region. Cairo: UNDP.

HeSSEL, STÉPHANE (2011): ¡Indignaos! Madrid: Destino.

INTERNATIONAL LABOUR FORCE (2012): Regional Report: National Events on Youth Employment in the Arab States. Youth Employment Programme.

Khouri, RAMi G. y DinA Shelata (2011): "Youth Civic and Political Participation. Apathy Amidst New Form of Activism». En: A Generation on the Move: Insights into the Conditions, Aspirations and Activism of Arab Youth. Beirut: Issam Fares Institute for Public Policy \& International Affairs.

MaliK, AdeEl y Bassem Awadallah (2013): «The Economics of the Arab Spring». Elsevier: World Development. Vol. 45.

NAVARRETE MORENO, LORENZO (Cood.) (2014): La emigración de los jóvenes españoles en el contexto de la crisis. Análisis y datos de un fenómeno difícil de cuantificar. Madrid: Instituto de la Juventud (INJUVE).

ORGANIZACIÓN INTERNACIONAL DEL TRABAJO (2012): Informe sobre el trabajo en el mundo 2012. Mejores empleos para una economía mejor. Ginebra: OIT.

Moreno, A.; A. López y SEgAdo (2012): «La transición de los jóvenes a la vida adulta. Crisis económica y emancipación tardía». Colección Estudios Sociales N³4. Barcelona: Obra Social La Caixa.

MuÑOZ, V. M. (2009): «Apuntes teóricos sobre la crisis del empleo juvenil». Revista de Estudios de Juventud $\mathrm{N}^{\circ} 87$. Madrid: INJUVE. 
OFICINA INTERNACIONAL DEL TRABAJO (2009): «Para recuperarse de la crisis: un pacto mundial para el empleo». Conferencia Internacional del Trabajo, en su nonagésima octava reunión, Ginebra, 19 de junio 2009.

RodríGueZ SAN JULIÁN, Elena y JUAN CARLOS BALleSteros (2013): Crisis y contrato social. Los jóvenes en la sociedad del futuro. Madrid: Centro Reina Sofía sobre Adolescencia y Juventud.

Soler, Pere, Anna Planas y Carles FeiXa (2014): Young People and Youth Policies in Spain in Times of Austerity: Between Juggling and the Trapeze. International Journal of Adolescence and Youth.

SUBIRATS, JOAN y MARGARITA LEÓN (2014): Repensant el concepte de treball. Quines ocupacions per a quins joves? Trobar feina o crear feina? Barcelona IGOP.

UneSCo/VV.AA. (2011): «Youth: Civic Engagement \& Economic Participation». Beirut: Regional Bureau for Education in the Arab States.

WORLD ECONOMIC FORUM/VV.AA. (2012): Perspectives on Youth Employment in the Arab World in 2012.

Young PeOPLE IN ARAB Countries (2010): Promoting Opportunities and Participation. Workshop 2010. Marsella: Banco Mundial.

\section{ARTÍCULOS DE PRENSA Y WEBS}

ANTENTAS, JOSEP y ESTHER VIVAS (2011): «Movimiento de 1@s indignad@s: pasar a la siguiente fase». ATTAC España, junio.

Disponible en: http://rebelion.org.

Belil CREIXELl, FRANCISCO (2014): «Cómo luchar contra el paro juvenil». El País, 12 de agosto 2014. Disponible en: www.caffereggio.net.

CRIADO, ENRIQUE MARTíN (2014): «El de los 'ninis' es un buen ejemplo de individualización de los problemas sociales». Àmbits de Política i Societat. Colegio de Sociólogos y Politólogos de Cataluña.

Disponible en: http://ambitscolpis.com.

NAVARRO, VicenC (2012): «¿Por qué y cómo surgió el 15-M?». Blog personal, 15 de mayo de 2012.

«El sur de Europa le enseña los dientes a la austeridad». Público, 14 de noviembre de 2012. Disponible en: www.publico.es.

«Juventud reformista». El País, 6 de mayo de 2014.

Disponible en: http://elpais.com.

«Los indignados de toda Europa salen a la calle para clamar contra el 'austericidio' de la troika». El Periódico, 1 de junio de 2013.

Disponible en: www.elperiodico.com.

«Otro rescate portugués». El País, 25 de agosto de 2014.

Disponible en: http://elpais.com. 